\title{
A Narrative Literature Review of Global Pandemic Novel Coronavirus Disease 2019 (COVID-19): Epidemiology, Virology, Potential Drug Treatments Available
}

\section{Venkatesh Balaji Hange*}

Department of Oral and Maxillofacial Surgery, K.D. Dental College \& Hospital, Mathura, Uttar Pradesh, India

*Corresponding author: Venkatesh Balaji Hange, Department of Oral and Maxillofacial Surgery, K.D. Dental College \& Hospital, Mathura, Uttar Pradesh, India, Tel: 7385051925; E-mail: Venkateshhange@yahoo.com

Received date: April 18, 2020; Accepted date: April 29, 2020; Published date: May 04, 2020

Citation: Hange VB (2020) A Narrative Literature Review of Global Pandemic Novel Coronavirus Disease 2019 (COVID-19): Epidemiology, Virology, Potential Drug Treatments Available. Arch Med Vol. 12 Iss.3:9

Copyright: (C2020 Hange VB. This is an open-access article distributed under the terms of the Creative Commons Attribution License, which permits unrestricted use, distribution, and reproduction in any medium, provided the original author and source are credited.

\section{Abstract}

Coronaviruses (CoVs) are the largest group of viruses belonging to the Nidovirales order, which includes Coronaviridae, Arteriviridae, Mesoniviridae and Roniviridae families. Coronavirus virion are circular with a diameter of nearly $125 \mathrm{~nm}$. Its most conspicuous characteristic of coronaviruses is the club-shaped spiked projections originating from the surface of the virion. Such spikes are a definite characteristic of the virion and give them a solar corona appearance leading the term coronaviruses [1]. Coronaviridae covers a broad range of host \& carriers, infecting many mammalian \& avian species/subspecies, this may affect the upper respiratory, gastrointestinal, hepatic and central nervous system via a number of diseases [2]. SARS-CoV, group $2 b-\beta$ coronavirus, was detected as the potential cause of the 2002-2003 outbreak of Severe Acute Respiratory Syndrome (SARS) in the Guangdong Province of China. In a cluster of highly pathogenic respiratory tract infections in Saudi Arabia and other Countries in the middle east throughout 2012, Middle East Respiratory Syndrome-CoV (MERS-CoV), was found to be the potential cause is an example of another novel human CoV [3]. On 31 December 2019, the Wuhan Health Commission in the Republic of China's Hubei Province notified the National Health Commission, China CDC and the WHO of a series of 27 cases of unexplained etiological pneumonia. Leaks have been predominantly tracked to the Huanan Seafood Wholesale Market in Wuhan, that trades fish and a myriad of livestock species comprising chickens, bats, marmots and snakes [4]. By January 7th, 2020 Chinese Center for Disease Control and Prevention officials had isolated severe acute respiratory syndrome coronavirus 2 (SARSCoV-2). On 11 February, WHO officially named the disease as the coronavirus disease 2019 (COVID-19) [5]. The World Health Organization (WHO) also announced a global emergency on January 31st due to increasing concern about its rapid expansion and the disease became listed as a pandemic by March 11th.
Keywords: SARS-COV2; COVID-19; Pandemic; Potential drug treatment

\section{Introduction}

Coronaviruses (CoVs) are the largest group of viruses belonging to the Nidovirales order, which includes Coronaviridae, Arteriviridae, Mesoniviridae, and Roniviridae families. Coronavirus virion are circular with a diameter of nearly $125 \mathrm{~nm}$. Its most conspicuous characteristic of coronaviruses is the club-shaped spiked projections originating from the surface of the virion. Such spikes are a definite characteristic of the virion and give them a solar corona appearance leading the term coronaviruses [1]. Coronaviridae covers a broad range of host \& carriers, infecting many mammalian \& avian species/subspecies, this may affect the upper respiratory, gastrointestinal, hepatic and central nervous system via a number of diseases [2].

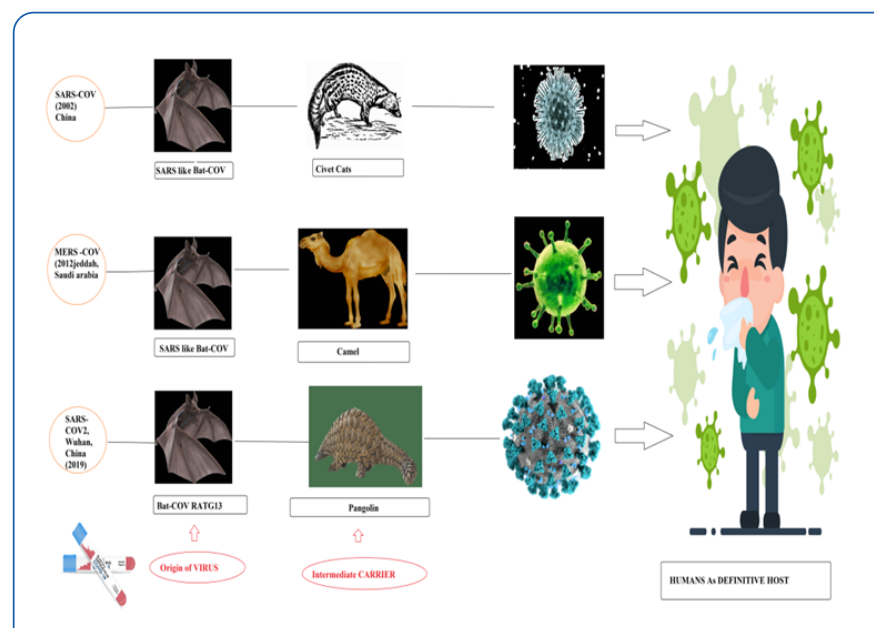

Figure 1 Comparison of SARS-CoV-2, SARS-CoV and MERSCoV with respect to epidemiology, virology \& etiology.

SARS-CoV, group $2 b-\beta$ coronavirus, was detected as the potential cause of the 2002-2003 outbreak of Severe Acute Respiratory Syndrome (SARS) in the Guangdong Province of 
China. In a cluster of highly pathogenic respiratory tract infections in Saudi Arabia and other Countries in the middle east throughout 2012, Middle East Respiratory Syndrome-CoV (MERS-CoV), (Figure 1) was found to be the potential cause is an example of another novel human CoV (Table 1) [3].

On 31 December 2019, the Wuhan Health Commission in the Republic of China's Hubei Province notified the National Health Commission, China CDC and the WHO of a series of 27 cases of unexplained etiological pneumonia. Leaks have been predominantly tracked to the Huanan Seafood Wholesale Market in Wuhan, that trades fish and a myriad of livestock species comprising chickens, bats, marmots and snakes [4]. By January 7th, 2020Chinese Center for Disease Control and Prevention officials had isolated severe acute respiratory syndrome coronavirus 2 (SARS-CoV-2). On 11 February, WHO officially named the disease as the coronavirus disease 2019 (COVID-19) [5]. The World Health Organization (WHO) also announced a global emergency on January 31st due to increasing concern about its rapid expansion and the disease became listed as a pandemic by March 11th [6].

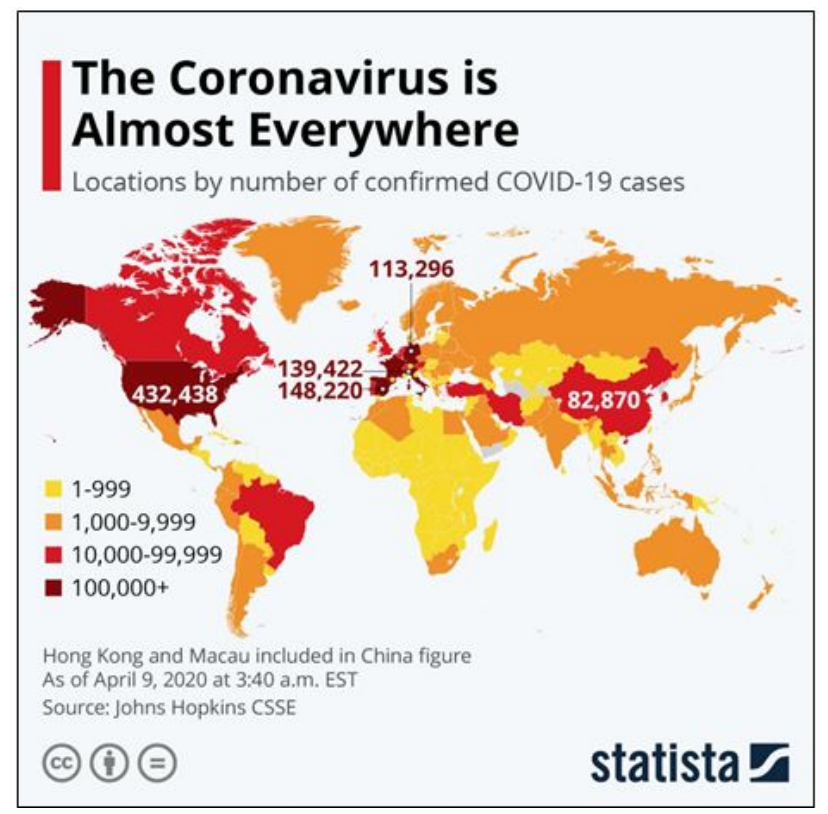

Figure 2 Informative graphics showing location \& number of confirmed cases as of April 9 2020. Image source obtained from Statista.

As per the World Health Organization (WHO), the Centers for Disease Control and Prevention (CDC), and the FDA, there are presently no drugs or vaccinations that are known to be successful for SARS-CoV-2 management or preventing the spread. Within clinical trials and compassionate use guidelines, numerous different compounds are used relying on in vitro activity (against SARS-CoV-2 or associated viruses) and on constrained clinical knowledge. There was no proven efficacy for any drug therapy [7].

As of April 13, 2020, COVID-19 has been recognized in 196 countries, with a total of 1,876,707 laboratory-confirmed cases, 435,591 recovered and 116,789 deaths. In India till 13th
April 2020, 9352 laboratory-confirmed cases, 980 recovered and 324 deaths were reported by Indian Council of Medical Research (Figure 2).

\section{Literature Review}

This narrative review discusses the relevant literature, including updated studies, Case series, protective measure, treatment guidelines and the implications for practice with respect to (novel Coronavirus, nCoV) infection. After performing a literature search using ProQuest, MEDLINE, and PUBMED, Google Scholar search engines. The search terms used were COVID-19, Coronaviruses, outbreak, "respiratory illness", "transmission", and "infection control and management". After reading the article titles and abstracts, full text, 43 articles were included based on the quality of the studies.

Table 1 Comparison of SARS-CoV-2, SARS-CoV, and MERS-CoV patients.

\begin{tabular}{|c|c|c|c|}
\hline \multicolumn{4}{|c|}{ Corona Viruses } \\
\hline & S.A.R.S- COV 2 & S.A.R.S- COV & M.E.R.S- COV \\
\hline $\begin{array}{l}\text { First } \\
\text { reported } \\
\text { date }\end{array}$ & December,2019 & $\begin{array}{l}\text { November, } \\
2002\end{array}$ & April,2012 \\
\hline $\begin{array}{l}\text { Outbrea } \\
\text { k site }\end{array}$ & $\begin{array}{l}\text { Wuhan City, Hubei } \\
\text { Region, China }\end{array}$ & $\begin{array}{l}\text { Guangdong, } \\
\text { China }\end{array}$ & $\begin{array}{l}\text { Jeddah city, Saudi } \\
\text { Arabia }\end{array}$ \\
\hline $\begin{array}{l}\text { Confirm } \\
\text { ed } \\
\text { cases }\end{array}$ & $\begin{array}{l}\text { 1,876,707 till } 13 \text { April } \\
2020\end{array}$ & 8096 & 2519 \\
\hline $\begin{array}{l}\text { Mortality } \\
\text { rate }\end{array}$ & $117,653(21 \%)$ & $744(10 \%)$ & $866(34.4 \%)$ \\
\hline $\begin{array}{l}\text { Incubati } \\
\text { on } \\
\text { period } \\
\text { (Days) }\end{array}$ & Jul-14 & 02-Jul & 05-Jun \\
\hline $\begin{array}{l}\text { Origin } \\
\text { host }\end{array}$ & $\begin{array}{l}\text { Chinese horseshoe } \\
\text { bats }\end{array}$ & $\begin{array}{l}\text { Chinese } \\
\text { horseshoe } \\
\text { bats }\end{array}$ & Bats \\
\hline \multirow[t]{2}{*}{$\begin{array}{l}\text { Carrier } \\
\text { host }\end{array}$} & pangolin & Civet cats & Camel \\
\hline & $\begin{array}{l}\text { fever, cough, myalgia } \\
\text { or fatigue, pneumonia, } \\
\text { and complicated } \\
\text { dyspnea, whereas } \\
\text { Less common include } \\
\text { headache, diarrhea, } \\
\text { hemoptysis, runny } \\
\text { nose, and phlegm } \\
\text { producing cough }\end{array}$ & $\begin{array}{l}\text { High fever, } \\
\text { headache, } \\
\text { Chills, } \\
\text { shortness of } \\
\text { breath, dry } \\
\text { Non- } \\
\text { productive } \\
\text { Cough in few } \\
\text { Cases } \\
\text { respiratory } \\
\text { failure. }\end{array}$ & $\begin{array}{l}\text { cough, fever, } \\
\text { rhinorrhea, } \\
\text { shortness } \\
\text { breath, } \\
\text { gastrointestinal } \\
\text { symptoms, } \\
\text { nausea, vomiting, } \\
\text { fatigue, and } \\
\text { myalgia, } \\
\text { respiratory failure. }\end{array}$ \\
\hline $\begin{array}{l}\text { Recepto } \\
r\end{array}$ & ACE2 & ACE2 & DPP4(CD26) \\
\hline Spread & $\begin{array}{l}\text { Droplet (Close) or } \\
\text { potentially distant } \\
\text { (aerosol) from } \\
\text { symptomatic \& } \\
\text { asymptomatic patients, } \\
\text { surface contamination, } \\
\text { faecal transmission }\end{array}$ & $\begin{array}{l}\text { Droplet } \\
\text { (Close) } \\
\text { symptomatic } \\
\text { patients, } \\
\text { surface } \\
\text { contamination } \\
\text {, }\end{array}$ & $\begin{array}{l}\text { Close contact with } \\
\text { infected animal or } \\
\text { animal products, } \\
\text { Limited human to } \\
\text { human } \\
\text { transmission via } \\
\text { close contact }\end{array}$ \\
\hline
\end{tabular}




\section{Geograp}

hy

196 countries

29 countries

27 countries

\section{Virology}

Coronaviruses belong to a family that comes under the order "Nidovirales". Nidovirales order includes the viruses that use a nested set of mRNAs for their replication. Further, the coronavirus sub-family has four genera (alpha, beta, gamma, and delta coronaviruses).

Beta-coronaviruses that carry the disease comprise HCoVHKU1, HCoV-OC43, Middle East respiratory coronavirus syndrome (MERSCoV), severe acute respiratory coronavirus syndrome (SARS-CoV), and SARS-CoV-2 [8]. Genomic and phylogenic research has shown that COVID-19 is a $\beta$ CoV-2, $\mathrm{CoV}$ of the same subgenus as SARS virus, but in a different clade .The constitution of the receptor-binding gene region is very like to that of the SARS-CoV, and the virus has been demonstrated to utilize the same receptor, the angiotensinconverting enzyme 2 (ACE2), for entrance into respiratory cells [9].

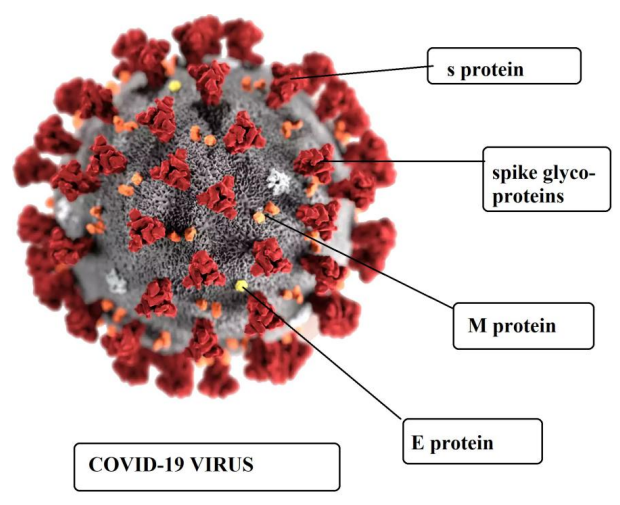

Figure 3 Structure of COVID-19 Virus.

Another one third of the genome contains four structural proteins (spike (S), envelope (E), membrane (M) nucleocapsid $(\mathrm{N})$, and some other helper proteins. The spike protein plays an important role in virus entry into the host. Initial interactions between the S1 domain and its host receptor (ACE2) in case of SARS-CoV \& SARS-CoV-2 [10]. The E protein is the smallest (8.4-12 kDa size) TM structural protein of CoV. The $E$ protein plays a crucial role in the morphogenesis of viruses, notably during acquisition as well as egress. Maintenance of the shape of the viral envelope is the most important function of the $M$ protein, and the $M$ protein performs this job by interacting with other $\mathrm{CoV}$ proteins. M protein also takes part in the sensitization of the host by the virus [11]. Formation and maintenance of the RNP complex are the most important functions of the $\mathrm{N}$ protein, it often controls viral RNA replication \& transcription, and in host, it inhibits protein translation through EF1amediated action. Hemagglutinin esterase is present in the envelope of CoV, more specifically among beta-coronaviridiae. The $\mathrm{HE}$ is a marker of $\mathrm{CoV}$ and influenza virus evolution [12]. E-protein plays a crucial role in the assembling and release of viruses. In addition, the Eproteins have several other roles, like the activation of the ion channel necessary for SARS-CoV pathogenesis, and presumably SARS-CoV-2 [9] (Figure 3).

The presence of this furin-like cleavage region in SARS-CoV-2 promotes the priming of $S$ proteins and may improve the performance of SARS-CoV-2 dissemination [8].

\section{Treatment and Management}

Drug repurposing is a feasible, quick and expense-effective approach that can solve the obstacles of the conventional de novo drug discovery and production by addressing various diseases and disorders. Drug repurposing, is the method of finding new applications for existing or candidate drugs is a successful drug development technique [13] (Figure 4).

As per the World Health Organization (WHO), the Centers for Disease Control and Prevention (CDC), and the FDA, there are presently no medicines or vaccinations that are believed to be likely to succeed for SARS-CoV-2 management or preventing the spread [7]. The only alternative available is to use wide-spectrum antiviral drugs such as nucleoside analogs, as well as HIV-protease inhibitors that can attenuate viral infection before the actual antiviral is available [14]. Pharmacological management of young, stable patients with minor symptoms and no inherent comorbid circumstances is usually not recommended [7].

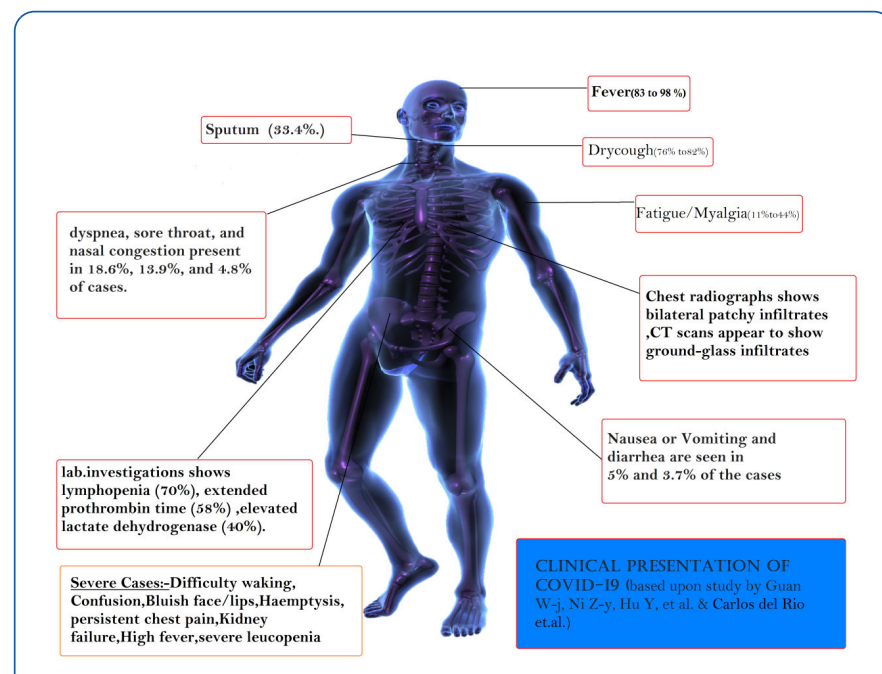

Figure 4 Clinical presentation of COVID-19.

The People's Republic of China's National Health Commission has supported the use of chloroquine phosphate to treat COVID-19 patients, in its revised guidelines for the prevention, diagnosis, and treatment of pneumonia developed due to COVID-19 infection in the vast populous country [13] (Figure 5).

Passive antibody transfer is one of the most effective and traditional tools used in most of the infectious outbreaks is the use of serum of patients who just recovered from the active 
viral infection to treat patients who contract in future [15]. Monoclonal antibodies will be used in passive immunotherapy as powerful bio therapeutics to overpower the SARS-CoV-2 and to control the harmful outcomes of COVID-19.Intravenous use of immunoglobulins can prove helpful in the therapy of SARS-CoV-2 induced pulmonary inflammation [13].

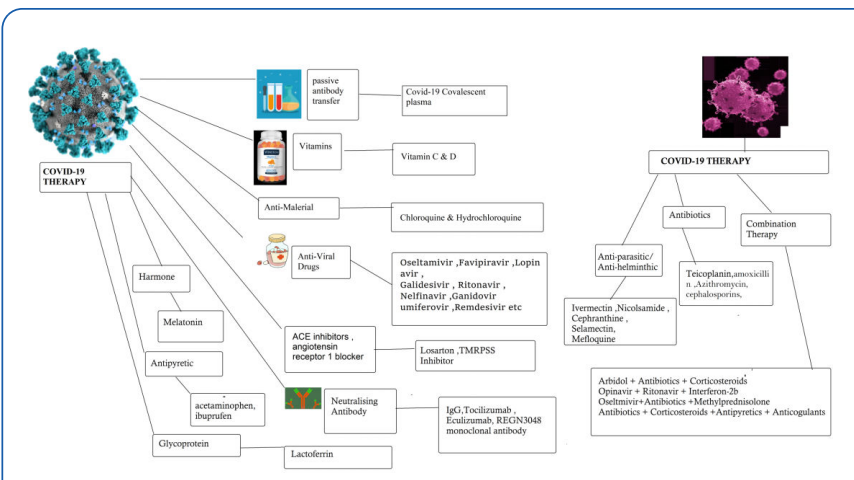

Figure 5 Drug treatment options available against COVID-19.

\section{Hormone: Melatonin}

Viruses generate an explosion of reactive oxygen species, and melatonin is the best natural antioxidant. Melatonin prevents the programmed death of cells that coronaviruses cause, causing significant damage to the lungs. Coronavirus causes inflammation in the lungs which requires inflammasome activity. Melatonin blocks the inflammasome. Fibrosis may be the most dangerous complication after COVID-19. Melatonin is known to prevent fibrosis [16].

Melatonin (N-acetyl-5-methoxytryptamine) is a bioactive compound with a spectrum of health-promoting characteristics; melatonin has indeed been widely used for the treatment of sleep disturbances, delirium, atherosclerosis, respiratory and viral infections. Melatonin is not viricidal but it has indirect anti-viral actions due to its anti-inflammation, anti-oxidation and immune enhancing features [17]. In drug trials, doses of $3 \mathrm{mg}, 6 \mathrm{mg}$, and $10 \mathrm{mg}$ of oral consumption of melatonin by ICU patients demonstrated adequate safety compared with placebo. Interestingly, even though melatonin was administered to individuals for a month at a dosage of 1 $\mathrm{g} / \mathrm{d}$, there were no detrimental treatment observations [18]. Thus melatonin can serve as a potential adjuvant treatment along with combination of the antiviral drugs lopinavir / ritonavir.

\section{Protein: Lactoferrin}

Lactoferrin (Lf) is the highly conserved pleiotropic ironbinding transferrin of glycoprotein family, which is expressed and secreted by glandular cells and found in most body fluids. Lf's anti-inflammatory and immunomodulatory role appears to be capable of moderating the response of the host to pathogens, and having dual capacity to activate the immune system to combat pathogenic infiltration while at the same time avoiding adverse immune and inflammatory responses [19].
Lf prone human pathogenic viruses known to be suppressed from Lf comprise DNA and RNA viruses: cytomegaloviruses, herpes simplex viruses, human immunodeficiency viruses (HIV), rotaviruses, polioviruses, respiratory syncytial viruses, hepatitis B and C (HCV) viruses, parainfluenza viruses, alphaviruses, hantaviruses, human papillomaviruses, adenoviruses, enteroviruses 71 , echoviruses 6 , influenza $A$ viruses, and Japanese viruses. Lactoferrin (Lf) is a naturally produced and non-toxic glycoprotein tested against a wide array of viruses including SARS-CoV, that is genetically similar to COVID-19-causing SARS-CoV-2 [20]. Lf doses ranging from $100 \mathrm{mg}$ to $4.5 \mathrm{~g}$ a day for various indications without apparent toxicities. Newer formulations of Lf including encapsulation and liposomalization have been explored [21], reportedly zincsaturated lactoferrin has a much more potent antiviral activity. This is of particular relevance in COVID-19 as zinc supplementation has been proposed as a possible supplemental intervention for the disease [22]. Passive antibody- COVID-19 convalescent plasma

Passive antibody transfer is one of the most effective and traditional tools used in most of the infectious outbreaks is the use of serum of patients who just recovered from the active viral infection to treat patients who contract in future. Patients recovering through active viral infections generate a polyclonal immune system response to varying SARS-CoV-2 antigens thus counteracting active viral infections and hence convalescentphase plasma can be used as a therapeutic alternative [15].

Patients eligible under then emergency Investigational New Drug Applications (elNDs):

- Must have laboratory confirmed COVID-19.

- Should have devastating or instantaneous life-threatening COVID-19 Severe infection described as: dyspnea, respiratory rate 30 breaths/minute or higher, blood oxygen saturation $93 \%$ or less, arterial oxygen partial pressure of less than 300 inspired oxygen ratio, and/or pulmonary infiltration of more than $50 \%$ in less than 24 to 48 hours.

- Life-threatening illness described as: respiratory failure, septic shock, malfunction or failure of multiple organs. IV) Must provide informed consent [7].

\section{Neutralizing antibody: Tocilizumab}

Tocilizumab is an Interleukin-6 (IL-6) Receptor-Inhibiting Monoclonal Antibody. Tocilizumab inhibits IL-6-mediated signaling by competitively binding to both soluble and membrane-bound IL- 6 receptors. IL- 6 is a pro-inflammatory cytokine implicated in myriad physiological processes, like the induction of T-cells, the initiation of immunoglobulin production, the stimulation of hepatic acute-phase protein synthesis, and the multiplication and differentiation of hematopoietic precursors. IL- 6 is generated by varying types of cells comprising T- and B-cells, lymphocytes, monocytes, and fibroblasts [23].

Tocilizumab first became authorized by the FDA for the treatment of rheumatoid arthritis in 2010. It received FDAapproval for severe or life-threatening CAR T-associated Cytokine-release syndrome (CRS) in 2017 due to its efficacy 
and safety profile [13]. $\mathrm{Xu} X$ et al. retrospective assessment analyzed 21 patients in whom tocilizumab was incorporated to standard COVID-19 therapy. Early data postulate that tocilizumab may have therapeutic benefit as an adjunctive treatment. Clinical symptoms, CT opacity changes, lymphocyte percentage, and C-reactive protein levels all improved in these patients [24]. The prescribed dose is $4-8 \mathrm{mg} / \mathrm{kg}$ or $400 \mathrm{mg}$ of the typical IV dose once and may be repeated in 12 hours (not to reach a maximum dose of $800 \mathrm{mg}$ ). Possible complications are risk of Gl perforation, risk of hepatotoxicity, Caution in patients with thrombocytopenia and neutropenia, Infusionrelated reactions [7]

\section{Antibiotics: Teicoplanin}

Teicoplanin, a glycopeptide antibiotic routinely used to treat bacterial infections, currently used in the treatment of Grampositive bacterial infections, especially staphylococcal infections. It has usefulness against myriad viruses like those of Ebola virus, influenza virus, flavivirus, hepatitis $C$ virus and Human Immunodeficiency Virus (HIV) and even coronavirus including Middle East coronavirus respiratory syndrome (MERS-CoV) as well as SARS-CoV [25].

According to Zhou et al. in coronaviruses teicoplanin works at the initial stage of the viral life cycle by impeding the low-pH cleavage of the viral spike protein by cathepsin $L$ in late endosomes, prohibiting the emergence of genomic viral RNA and the progression of the virus replication process [26].

Zhang J et al. showed that Teicoplanin has anti-viral activity against SARS-Cov-2 in their study. The concentration of teicoplanin required to inhibit $50 \%$ of viruses (IC 50) in vitro was $1.66 \mu \mathrm{M}$, which is much lower than the concentration reached in human blood ( $8.78 \mu \mathrm{M}$ for a daily dose of $400 \mathrm{mg}$ ) [27].

Thus teicoplanin may potential candidate for alternative drugs used against COVID-19.

\section{Harmone: IgG}

Immunoglobulin $\mathrm{G}$ has been prescribed as a treatment in critical patients with COVID-19. FcR plays a role in pulmonary inflammation; thus, blocking FcR activation will reduce inflammatory damage to COVID-19.Thus intravenous use of immunoglobulins can prove helpful in the therapy of SARSCoV-2 induced pulmonary inflammation [28].

The efficacy of IVIG could be better if the IgG antibodies were gathered from cases improved from SARSCoV-2 infection, so as to increase the probability of inactivating the virus. This is called as 'convalescent immune plasma' therapy. Immunotherapy with specific IgG antibodies along with antiviral drugs can be an alternative therapy against COVID-19 disease until better choices e.g., vaccine are accessible [9].

\section{Nucleotide analogue: Remdesivir (GS-5734)}

Remdesivir is a new nucleotide analogue that has effect against SARS-CoV- 2 in vitro and linked coronaviruses (including
SARS and MERS-CoV) both in vitro and in animal studies. Remdesivir is an investigational monophosphoramidate prodrug of an adenosine analog [9]. Remdesivir is a monophosphoramidate prodrug of remdesivir-triphosphate (RDV-TP), an analogous adenosine, which functions as an RNAdependent polymerase inhibitor (RdRps). Remdesivir-TP competes with adenosine-triphosphate for incorporation into nascent viral RNA chains, once incorporated into the viral RNA at position I, RDV-TP terminates RNA synthesis at position i+3. Because RDV-TP does not cause imimmediate chain termination [7].

Wang $\mathrm{M}$ et al. in vitro study showed that remdesivir has significant activity against coronavirusCOVID-19 and a high genetic barrier to resistance. Remdesivir attains potent antiviral action towards SARS-CoV-2 clinical isolates; [HalfMaximum Effective Concentration (EC50) $=0.77$ mcgM, HalfCytotoxic Concentration (CC50) $>100$ mcgM, Selective Index (SI) $>129.87]$ [29].

The drug has a long intracellular half-life that allows for once daily dosing. The dosage being investigated for COVID-19 has been $200 \mathrm{mg}$ intravenously (IV) on day 1 followed by $100 \mathrm{mg}$ IV each day for up to 10 days, infused for more than $30-60$ minutes [30].

\section{Anti-virals: Lopinavir and Ritonavir}

Lopinavir is indeed a protease antagonist of human immunodeficiency virus 1 (HIV-1) provided in a fixed-dose combination with ritonavir (LPV/r), a formidable CYP3A4 inhibitor which "augments" lopinavir concentrations. Lopinavir tends to suppress the primary SARS-CoV-1 protease, which prohibits viral replication [30]. Lopinavir and ritonavir may bind to Mpro, a key enzyme for coronavirus replication. This may suppress coronavirus activity.

Lopinavir; Ritonavir in a dose of $400 \mathrm{mg} / 100 \mathrm{mg}$ (2 capsules/ tablets) by mouth twice a day for no more than 10 days is recommended according to Chinese SARS-CoV-2 guidelines. In pediatric patients weighing $15-40 \mathrm{~kg}$, the recommended dose is $10 \mathrm{mg} / \mathrm{kg}$ suspension by mouth twice daily according to the United States guidelines [31].

Safety Concern regarding Lopinavir; Ritonavir are Risk of cardiac arrhythmias (e.g., QT prolongation), Caution in patients with hepatic disease or hepatitis, significant drug interactions. Cao B et al. conducted comparative study of Lopinavir; Ritonavir used single-agent or combination with either ribavirin or interferon- $\alpha$ in in adults hospitalized with severe COVID-19.

There was a statistically significant difference in the time to clinical improvement between the two groups on day 14 but this result was not statistically significant on day 28 . The mortality at 28 days reduced by $5.8 \%$ and the length of stay in the ICU reduced by five days with the lopinavir-ritonavir treatment [32]. 


\section{Vitamin D}

Vitamin $D$ is a steroid hormone which may be synthesized endogenously from the effect of UVB irradiation on skin, or consumed from exogenous dietary sources or supplements. Vitamin $D$ is responsible for reducing the immunity acquired and regenerating the endothelial lining. This may be beneficial in minimizing the alveolar damage caused in ARDS [33,34].

Systematic review and meta-analysis by Martineau AR et al. showed that level I findings $(N=11,321)$ revealed that vitamin $D$ supplementation has a 12 percent cumulative therapeutic benefit against bacterial and viral acute respiratory tract infection (adjusted $\mathrm{OD}=0.88$, $\mathrm{p}$ patients on a regular or weekly vitamin $D$ regimen relative to those consumed on a monthly vitamin $D$ bolus (adjusted $O D=0.81, p=0.001$ ) [33]. Recommend intakes of Vitamin-D, is 20 micrograms per day and 37.5-50 micrograms per day respectively for older adults as per U.S. Standards [34].

\section{Vitamin C}

Vitamin C is well recognised for its antioxidant properties, which can harvest hazardous reactive oxygen species and thereby safeguard the cells as well as tissues of the body from oxidative damage and malfunction [35]. Vitamin C (L-ascorbic acid) has a defensive effect of high-dose intravenous vitamin $C$ (HDIVC) throughout ARDS-induced sepsis. Vitamin C enhances the conservation of the alveolar epithelial barrier and transcribes the protein channels (CFTR, aquaporin-5, ENaC, and $\mathrm{Na}+\mathrm{K}+$ ATPase) to control alveolar fluid clearance [34]. Randomized randomized trial involving Fowler AA 3rd, Truwit JD et al. 167 patients with sepsis-related ARDS demonstrated that 4-day administration of $\sim 15 \mathrm{~g} /$ day of IV vitamin C could reduce mortality in such patients [36].

A randomized controlled trial (RCT) was performed at the Zhongnan Hospital (NCT04264533) on 14 February 2020 to assess the clinical effectiveness and protection of vitamin $C$ in SARSCoV-2 viral pneumonia. They believe that vitamin $\mathrm{C}$ injection can enhance the prognosis of serious acute respiratory tract infections. The treatment arm requires a 7 day infusion of $12 \mathrm{~g}$ vitamin $\mathrm{C}(\mathrm{q} 12 \mathrm{~h}$ ) and the primary result tests ventilation-free days. The expected time for fulfillment is September 2020 [34].

\section{NSAIDs}

That coronaviruses of the acute respiratory syndrome SARSCoV and SARS-CoV-2 bind to targeting cells by the 2-converting angiotensin enzyme (ACE 2), generated by lung, intestine, kidney and blood vessel epithelial cells, Thus, the theory was raised that the management of diabetes and hypertension with ACE2 stimulant drugs raises the risk of severe and fatal COVID-19.Ibuprofen has been seen to upregulate ACE2 receptors and SARS-CoV-2 utilizes it to reach the cells where it amplifies [37]. Acetaminophene is first-line antipyretic Repeated prescriptions typically involve: oral acetaminophen, 10-15 mg/kg, 4-6 times / day. There is no current evidence indicating that ibuprofen worsens the clinical course of
COVID-1. The current standpoint of the WHO is to continue the use of ibuprofen as antipyretic agent $[9,34]$.

\section{Corticosteroids}

Corticosteroid medication for viral pneumonia is not suggested, but use has been taken into consideration in patients with refractory shock [7]. The explanation behind all this strategy is that the corticosteroids extend the viral shedding cycle and sustain a widespread anti-inflammatory environment that minimizes ARDS occurrence, dyspnea and severe pneumonia [34]. The WHO / CDC advise them not be given in COVID-19 disease with pneumonia except for there are other indications (e.g., exacerbation of chronic obstructive pulmonary disease, asthma, etc.) Chinese guidelines also advocate short term therapy with low-to-moderate dose steroids for ARDS complication of COVID-19 disease. Corticosteroids can be administered in a short period of time (3-7 days). The suggested dose of methylprednisolone should not surpass $1-2 \mathrm{mg} / \mathrm{kg} /$ day [9].

\section{Anti-parasitic agents: Ivermectin}

Ivermectin is an FDA-approved broad spectrum antiparasitic agent, shown to have anti-viral activity against a broad range of viruses in vitro [38]. Study by Leon Caly et al. Ivermectin has an antiviral effect towards clinical isolate SARSCoV-2 in vitro, with a single dose capable of regulating viral replication across $24-48 \mathrm{~h}$ throughout the system. They hypothesize that this is likely through inhibiting IMPa/b1mediated nuclear import of viral proteins. A single Ivermectin therapy capable of $\sim 5000$-fold virus depletion in cell culture at 48 hours. Ivermectin is FDA-approved for parasite infections and therefore has the capacity for re purposing. Ivermectin is readily available, as it is included in the WHO model list of essential medicinal goods [39].

\section{Antiviral agents: Umifenovir, Oseltamivir, Arbidol and Nitazoxanide}

Arbidol, an effective antiviral against SARS-CoV in combination with antibiotics (moxifloxacin or levofloxacin, nemonoxacin, linezolid, azithromycin or amoxicillin), corticosteroids and oxygen therapy has been used in COVID-19 therapy Arbidol available in Russia and China. Arbidol is given orally to adults at a dosage of $200 \mathrm{mg}, 3$ times a day. Treatment period is no greater than 10 days $[9,22]$.

Umifenovir is a non-nucleoside broad-spectrum antiviral licensed for influenza treatment and prophylaxis in Russia and China. Umifenovir is a membrane fusion inhibitor. Current regimens of Umifenovir used in China include a PO dose of 200 mg TDS for a duration of 10 days [40].

Neuraminidase inhibitors are known to reduce viral shredding in respiratory secretions and is used for prophylaxis against influenza. In a systematic review by Cochrane, Jefferson et al. found that Oseltamivir declined symptomatic influenza by 55 percent and Zanamavir by 61 percent [41]. Huang et al. used antibiotics, methylprednisolone 
corticosteroid (40-120 mg per day), and oseltamivir (orally 75 mg twice daily) in COVID-19 patients along with oxygen support. Combination with oseltamivir and other antiinfluenza medications may be required for coinfections with Influenza A/B [13].

Nitazoxanide has demonstrated potent in vitro activity against SARS CoV-2, with an EC50 at 48 hours of $2.12 \mu \mathrm{M}$ in Vero E6 cells. In comparison to coronaviruses, nitazoxanide demonstrates broad spectrum of antiviral behavior in vitro against influenza, respiratory syncytial virus, parainfluenza, rotavirus, and norovirus among several others. In an outpatient influenza study, a $600 \mathrm{mg}$ oral dose of nitazoxanide BID has been strongly linked with a 1-day improved performance in time to symptoms resolution compared to placebo $(p=0.008)$.In a study by Wang $M$ et al. nitazoxanide were effective against SARS CoV-2 in vitro [30].

\section{Antimalarials}

Chloroquine: Chloroquine, an antimalarial agent with antiinflammatory and immunomodulatory activities. In viruses, chloroquine can inhibit $\mathrm{pH}$-dependent stages of replication. Furthermore, chloroquine's immunomodulation is dependent on the suppression of cytokines (IL- 6 and TNF- $\alpha$ ) production and dissemination. Moreover, experiments with monkey cell line (Vero E6) showed that chloroquine interferes with the receptor glycosylation and thereby affects the entry mechanism of SARS-CoV-2 [34].

Yao $\mathrm{X}$ et al. demonstrated result of a study that chloroquine and hydroxychloroquine inhibit SARS-CoV-2 in vitro with hydroxychloroquine $(E C 50=0.72 \% \mu \mathrm{M})$ found to be more potent than chloroquine $(\mathrm{EC50}=5.47 \% \mu \mathrm{M})$ in vitro [42].

These findings have supported the clinical use of chloroquine, at a dose of $500 \mathrm{mg}$ by mouth twice daily, in numerous clinical trials in China during this outbreak. An in vivo study by Per Gao and colleagues, demonstrated, Chloroquine phosphate is superior to control medication to control pneumonia exacerbation, enhance pulmonary imaging results, facilitate virus-negative conversion and reduce the duration of disease. Severe adverse reactions to chloroquine phosphate were not noted in the aforementioned patients [30].

Side effects \& safety concerns includes risk of cardiac arrhythmias (e.g., QT prolongation), risk of retinal damage, especially with long term use, Caution in patients with G6PD deficiency, Caution in diabetics, Significant drug interactions [7]

Hydroxychloroquine: Hydroxychloroquine, a compound that differs from chloroquine only by a single hydroxyl group having better tolerability than chloroquine, which has led to longterm usage in rheumatological disorders. clinical safety profile is better than that of chloroquine and allows higher daily dose and has fewer concerns about drug-drug interactions [30].

Mechanisms might include suppression of viral enzymes or processes like those of viral DNA and RNA polymerase, glycosylation of viral proteins, aggregation of viruses, transportation of new virus particles and release of viruses. Certain mechanisms might include cellular receptor inhibition of ACE2, surface acidification of the cell membrane hindering virus fusion, and cytokine release immunomodulation [7]. Yao $X$ et al. suggested dosing PO hydroxychloroquine $400 \mathrm{mg}$ BID for the first day and then $200 \mathrm{mg}$ BID for the following four days from in vitro study. Gautret et al. recommended oral hydroxychloroquine sulfate $200 \mathrm{mg}$, three times per day during ten days as per their in vivo study $[30,42,43]$.

Side effects \& safety concerns includes risk of cardiac arrhythmias, Caution in patients with G6PD deficiency, risk of retinal damage, especially with long term use, Caution in diabetics, significant drug interactions [7,13,34] (Table 2).

Table 2 Drug treatment available against novel coronavirus-induced pneumonia.

\begin{tabular}{|c|c|c|c|}
\hline Drugs & Dosage & Mode of administration & Duration of treatment \\
\hline IFN- $\alpha$ & 5 million $U$ or equivalent dose each time, 2 times/day & Vapour inhalation & No more than 10 days \\
\hline Lopinavir/ritonavir & 200 mg/50 mg/capsule, Two capsules every time, twice a day & Oral & No more than 10 days \\
\hline Ribavirin & $\begin{array}{l}500 \mathrm{mg} \text { each time, } 2 \text { to } 3 \text { times/day in combination with IFN- } \alpha \\
\text { or lopinavir/ritonavir }\end{array}$ & Intravenous infusion & No more than 10 days \\
\hline Chloroquine phosphate & $\begin{array}{l}\text { Each day, } 2 \text { times a day, chloroquine phosphate } 500 \text { mg ( } 300 \\
\text { mg chloroquine) }\end{array}$ & Oral & No more than 10 days \\
\hline Arbidol & $200 \mathrm{mg}$ each time, 3 times/day & Oral & No more than 10 days \\
\hline hydroxychloroquine sulfate & $200 \mathrm{mg}$, three times per day during ten days & oral & No more than 10 days \\
\hline Oseltamivir & 75 mg twice daily & Oral & - \\
\hline Umifenovir & $200 \mathrm{mg}$ TDS & Oral & for a duration of 10 days \\
\hline Nitazoxanide & $600 \mathrm{mg}$ by mouth BID & Oral & - \\
\hline Methylprednisolone & $1-2 \mathrm{mg} / \mathrm{kg} / \mathrm{day}$. & Oral & 3-7 days \\
\hline Acetaminophen & $10-15 \mathrm{mg} / \mathrm{kg}, 4-6$ times /day & Oral & No more than 10 days \\
\hline
\end{tabular}




\begin{tabular}{|l|l|c|}
\hline vitamin $\mathrm{C}$ & $12 \mathrm{~g}$ infusion $(\mathrm{q} 12 \mathrm{~h})$ & Intravenous infusion \\
\hline Vitamin-D & $\begin{array}{l}20 \text { micrograms per day and } 37.5-50 \text { micrograms per day } \\
\text { respectively for older adults }\end{array}$ & Oral \\
\hline Teicoplanin & daily dose of $400 \mathrm{mg}$ & Oral \\
\hline Melatonin & $\begin{array}{l}3 \mathrm{mg}, 6 \mathrm{mg} \text { and } 10 \mathrm{mg}(\text { dose of } 1 \mathrm{~g} / \mathrm{d} \text { for a month, there was no } \\
\text { adverse reports of the treatment) }\end{array}$ & Oral \\
\hline Tocilzumab & $\begin{array}{l}4-8 \mathrm{mg} / \mathrm{kg} \text { or } 400 \mathrm{mg} \text { standard dose IV once, with the option to } \\
\text { repeat a dose in } 12 \text { hours (not to exceed a total dose of } 800\end{array}$ & - \\
\hline Lactoferrin & Intravenous infusion & - \\
\hline
\end{tabular}

\section{Interferons}

IFN- $\alpha$ is a broad-spectrum antiviral that is usually used for the treatment of hepatitis. Interferons may stimulate inherent antiviral reactions and are anticipated to have in vitro activity against SARS-CoV-2, considering the previously known activity exhibited against MERS-CoV. Chinese guidelines recommend ribavirin $500 \mathrm{mg}$ IV 2-3 times daily in combination with lopinavir/ritonavir or inhaled INF- $\alpha$ (5 million units nebulized twice daily) as one of the "standard treatment" options for COVID-19 [30].

Interferon (IFN)- $\alpha$ can decrease viral load during the early stage of COVID-19 disease and it can help to improve disease manifestasions and curtail the course of infection however toxicities are substantial including severe cytopenias, hepatoxicity (including fatality), neuropsychiatric events, and risk of developing fatal or life-threatening ischemia or infection [9].

(IFN)- $\alpha$ nebulization: $200,000-400,000 \mathrm{IU} / \mathrm{kg}$ or $2-4 \mu \mathrm{g} / \mathrm{kg}$ in $2 \mathrm{~mL}$ of sterile water, twice daily for 5-7 days; OR IFN- $\alpha 2 \mathrm{~b}$ inhalation (puff): dispensed to high-risk persons in close contact with presumed SARS-CoV-2 infected cases or those in the early phase with only upper airway expressions. Cases should be administered bilaterally 1-2 puffs in the nasal cavity, 8-10 puffs in the oropharynx, and 8,000 IU per 1-2 hours for each application, i.e., 8-10 puffs/day for 5-7 days [44].

\section{Discussion and Conclusion}

The latest outbreak of COVID-19 was deemed a pandemic by W.H.O. As of 24 March 2020, COVID-19, As of April 13, 2020, COVID-19 has been recognized in 196 countries, with a total of $1,876,707$ laboratory-confirmed cases, 435,591 recovered and 116,789 deaths. Till this date 9352 laboratoryconfirmed cases, 980 recovered and 324 deaths were reported by Indian Council of Medical Research in India.

Until now, no effective antiviral drug or vaccine has been identified for the treatment of COVID-19. Drug repurposing is a highly touted, quick and price-effective method which can resolve the conventional de novo drug discovery and innovation obstacles of COVID-19. Passive antibody transfer is one of the most effective and traditional tools used in most of the infectious outbreaks are the use of serum of patients who just recovered from the active viral infection to treat patients who contract in future. Passive antibody transfer has given encouraging results against latest outbreak of COVID-19. Widespectrum antiviral drugs such as nucleoside analogs, as well as HIV-protease inhibitors shown to attenuate COVID-19 viral infection in various in vitro \& in vivo study and are widely used until more definitive therapy or vaccine discovery against COVID-19.

Drugs such as melatonin can serve as a potential adjuvant treatment along with combination of the antiviral drugs lopinavir/ritonavir, Lactoferrin has anti-inflammatory and immunomodulatory against COVID-19 \& supplementation has been proposed. Vitamin C \& D having antioxidant properties has been used as adjuvant treatment along with combination of the antiviral. In near future conclusive drug treatment and vaccine against COVID-19 expecting to be developed, until then prevention is the gold standard approach against the novel corona virus.

\section{References}

1. Anthony RF, Stanley P (2020) Coronaviruses: An overview of their replication and pathogenesis. Coronaviruses. pp: 1-23.

2. Gallagher TM, Buchmeier MJ (2001) Coronavirus spike proteins in viral entry and pathogenesis. Virology. 279: 371-374.

3. Zaki AM, Van Boheemen S, Bestebroer TM, Osterhaus AD, Fouchier RA (2012) Isolation of a novel coronavirus from a man with pneumonia in Saudi Arabia. N Engl J Med. 367: 1814-1820.

4. Lu H, Stratton C, Tang Y (2020) Outbreak of pneumonia of unknown etiology in Wuhan, China: the mystery and the miracle. J Med Virol. 92: 401-402.

5. https: //www.who.int/docs/defaultsource/coronaviruse/ situation-reports/20200308-sitrep-48-COVID-19.pdf? sfvrsn=16f7ccef_4

6. Rismanbaf A (2020) Potential Treatments for COVID-19; a Narrative Literature Review. Arch Acad Emerg Mede. 8: e29.

7. Tim S, Jennifer B, Aimée L, Tony P (2020) COVID-19 Drug Therapy. Elsevier.

8. Rabaan AA, Al-Ahmed SH, Haque S, Sah R, Tiwari R, et al. (2020) SARS-CoV-2, SARS-CoV, and MERS-CoV: a comparative overview. Infez Med. 28: 174-184.

9. Özdemir Ö (2020) Coronavirus Disease 2019 (COVID-19): Diagnosis and Management (Narrative review). Med J. 
10. Li F (2016) Structure, function, and evolution of coronavirus spike proteins. Annu Rev Virol. 3: 237-261.

11. Prajapat M, Sarma P, Shekhar N, Avti P, Sinha S, et al. (2020) Drug targets for corona virus: A systematic review. Indian J Pharmacol. 52: 56-65.

12. Zeng $Q$, Langereis MA, van Vliet AL, Huizinga EG, De Groot RJ (2008) Structure of coronavirus hemagglutininesterase offers insight into corona and influenza virus evolution. Proc Natl Acad Sci USA. 105: 90659069.

13. Ali AR, Al-Ahmed SH, Sah R, Tiwari R, Yatoo MI, et al. (2020) SARS-CoV-2/COVID-19 and Advances in Developing Potential Therapeutics and Vaccines to Counter this Emerging Pandemic Virus- A Review. Front Immunol.

14. Wang M, Cao R, Zhang L, Yang X, Liu J, et al. (2020) Remdesivir and chloroquine effectively inhibit the recently emerged novel coronavirus (2019-nCoV) in vitro. Cell Res. 30: 269-271.

15. Mire CE, Geisbert JB, Agans KN, Thi EP, Lee AC, et al. (2016) Passive Immunotherapy: assessment of convalescent serum against ebola virus makona infection in nonhuman primates. J Infect Dis. 214: S367-S374.

16. Shneider A, Kudriavtsev A, Vakhrusheva A (2020) Can melatonin reduce the severity of COVID-19 pandemic? Int Rev Immunol.

17. Rui Z, Xuebin W, Leng N, Xiao D, Baitao M, et al. (2018) COVID-19: Melatonin as a potential adjuvant treatment. Life Sciences.

18. Mistraletti G, Sabbatini G, Taverna M, Figini MA, Umbrello M, et al. (2010) Pharmacokinetics of orally administered melatonin in critically ill patients. J Pineal Res. 48: 142-147.

19. https://www.researchgate.net/publication/340464937

20. Chen Y, Liu Q, Guo D (2020) Emerging coronaviruses: Genome structure, replication, and pathogenesis. J Med Virol.

21. Ishikado A, Imanaka H, Takeuchi T, Harada E, Makino T (2005) Liposomalization of lactoferrin enhanced it's anti-inammatory effects via oral administration. Biol Pharm Bull. 28: 1717-1721.

22. Zhang L, Liu Y (2020) Potential interventions for novel coronavirus in China: A systematic review. J Med Virol. 92: 479-490.

23. https: //www.accessdata.fda.gov/drugsatfda_docs/label/ 2013/125276s092lbl.pdf

24. http: //www.chinaxiv.org/user/download.htm?id=30387

25. Zhou N, Pan T, Zhang J, Li Q, Zhang X, et al. (2016) Glycopeptide antibiotics potently inhibit cathepsin $\mathrm{L}$ in the late endosome/ lysosome and block the en- try of Ebola virus, Middle East respiratory syndrome coronavirus (MERS-CoV), and severe acute respiratory syndrome coronavirus (SARS-CoV). J Biol Chem. 291: 9218-9232.

26. Baron SA, Devaux C, Colson P, Raoult D, Rolain JM (2020)Teicoplanin: An alternative drug for the treatment of COVID-19? Int J Antimicrob Agents. 55: 105944.

27. Zhang J, Ma X, Yu F, Liu J, Zou F, et al. (2020) Teicoplanin potently blocks the cell entry of 2019-nCoV. bioRxiv.

28. Cynthia L, Qiongqiong Z, Yingzhu L, Linda VG, Steve PW, et al. (2020) Research and development on therapeutic agents and vaccines for COVID-19 and Related Human Coronavirus Diseases. ACS Cent Sci. 6: 315-331.

29. Wang M, Cao R, Zhang L (2020) Remdesivir and chloroquine effectively inhibit the recently emerged novel coronavirus (2019-nCoV) in vitro. Cell Research. 30: 269-271.

30. McCreary EK, Jason MP (2020) COVID-19 Treatment: A review of early and emerging options.

31. Young BE, Ong SWX, Kalimuddin S (2020) Epidemiologic features and clinical course of patients infected with SARS-CoV-2 in Singapore. Jama.

32. Cao B, Wang Y, Wen D, Liu W, Wang J, et al. (2020) A trial of lopinavir-ritonavir in adults hospitalized with severe COVID-19. N Engl J Med.

33. Martineau AR, Jolliffe DA, Hooper RL, Greenberg L, Aloia JF, et al. (2017) Vitamin D supplementation to prevent acute respiratory tract infections: systematic review and meta-analysis of individual participant data. BMJ. 356: i6583.

34. Pramath K, Nagham Kaka, Baig MN (2020) A Comprehensive literature review on the clinical presentation, and management of the pandemic coronavirus disease 2019 (COVID-19). Cureus. 12: e7560.

35. Anitra CC (2020) A new clinical trial to test high-dose vitamin $C$ in patients with COVID-19. Critical Care. 24:133.

36. Fowler AA, Truwit JD, Hite RD, Morris PE, DeWilde C, et al. (2019) Effect of vitamin C infusion on organ failure and biomarkers of inflammation and vascular injury in patients with sepsis and severe acute respiratory failure: the CITRIS-ALI randomized clinical trial. JAMA. 322: 1261-1270.

37. Michal P (2020) Nonsteroidal anti-inflammatory drugs (NSAIDs) in COVID-19 patient, Disaster Emerg Med J 5: 2.

38. Aránzazu GC, Ana MSP, José M DL, Nélida FM, Matilde SV, et al. (2008) The pharmacokinetics and interactions of ivermectin in humans-a mini-review. AAPS J. 10: 42-6.

39. Leon Caly, Julian DD, Mike GC, David AJ, Kylie MW (2020) The FDA-approved Drug Ivermectin inhibits the replication of SARSCoV-2 in vitro. Antiviral Research. 178: 104787.

40. Dong L, Hu S, Gao J (2020) Discovering drugs to treat coronavirus disease 2019 (COVID-19). Drug Discov Ther. 14: 58-60.

41. Sumita A, Akhil DG, Nitesh G (2020) Emerging prophylaxis strategies against COVID-19. Monaldi Arch Chest Dis. 90: 1289.

42. Gautret P, Lagier JC, Parola P, Hoang VT, Meddeb L, et al. (2020) Hydroxychloroquine and azithromycin as a treatment of COVID19: results of an open-label non-randomized clinical trial. Int J Antimicrob Agents. In Press.

43. Xueting Y, Fei Y, Miao Z, Cheng C, Baoying H, et al. (2020) In vitro antiviral activity and projection of optimized dosing design of hydroxychloroquine for the treatment of severe acute respiratory syndrome coronavirus 2 (SARS-CoV-2). Clin Infect Dis.

44. Wang BX, Fish EN (2019) Global virus outbreaks: Interferons as 1st responders. Semin Immunol. 43: 101300. 